\title{
DIREITOS HUMANOS E AS PERSPECTIVAS DO BIODIREITO: A PROMOÇÃO DA EMANCIPAÇÃO SOCIAL POR MEIO DA TECNOLOGIA ASSISTIVA NO BRASIL
}

\author{
HUMAN RIGHTS AND THE BIOLAW PROSPECTS: THE PROMOTION OF \\ SOCIAL EMANCIPATION THROUGH ASSISTIVE TECHNOLOGY IN BRAZIL
}

\author{
${ }^{1}$ Eduardo Pordeus Silva
}

\section{RESUMO}

Esta pesquisa lança reflexões acerca dos direitos humanos em face da necessidade de fomento à tecnologia assistiva no Brasil. Parte-se da seguinte: é possível a plena emancipação social das pessoas com deficiência física ou mobilidade reduzida dado o acesso às tecnologias assistivas de que necessitam. Consequentemente, uma vez propiciadas a acessibilidade e os mecanismos físicos aptos a facilitar o direito à liberdade e o direito de igualdade de oportunidades, o Estado adotaria seu papel de fortalecer a ideologia de direitos humanos pautada na inclusão social. Eis que há grupos vulneráveis carecedores da proteção estatal no sentido de terem acesso ao direito de viver com dignidade e, portanto, ter acesso aos bens e serviços públicos. Reconhece-se que o surgimento dos novos sujeitos de direitos (a exemplo das pessoas com deficiência física ou mobilidade) são, assim, importantes no processo de consolidação de espaços democráticos e de cidadania, visto que se compreende a efetividade dos direitos enquanto obrigação estatal de promovê-los com o apoio da sociedade como um todo.

Palavras-chave: Direitos humanos, Tecnologia assistiva, Pessoas com deficiência, Efetividade, Estado

\begin{abstract}
This research brings reflections about human rights facing the assistive technology promotion's necessity in Brazil. Begins with: It is possible the complete social emancipation of people with physical disabilities or reduced mobility with the assistive tecnologies they need. Consequently, once they have acessibility and the physical mechanisms to make easier to have the right to freedom and the right to equal opportunities, the State would play his part in making the human rights ideology guided by social inclusion. There are vulnerable groups needing the protection that comes from the State and gives the right to live with dignity and also the access to public goods and services. It is recognized the new subjects of rights' appearance (e.g. people with phisical disabilities or reduced mobility); they are important in this consolidation process of democratic spaces and citizenship, because it is comprehensible the rights effectiveness when it happens by the State's obligation to promote them with the society support as a whole.
\end{abstract}

Keywords/Palabras-claves/Mots-clés: Human rights, Assistive technology, People with physical disabilities, Effectiveness, State

\footnotetext{
${ }^{1}$ Doutor em Ciências Sociais pela Universidade Federal do Rio Grande do Norte - UFRN, Natal, (Brasil). E-mail: tutortreinamento@gmail.com
} 


\section{INTRODUÇÃO}

Apresentamos algumas considerações teóricas, no campo jurídico, que permitem discutir, criticamente, as consequências da pós-modernidade, mediante a compreensão da importância fática dos direitos humanos na nova ordem global. Para tanto, busca-se articular os eixos elementares que embasam a teoria dos direitos fundamentais na perspectiva póspositivista, levando em conta a questão do biodireito e a inclusão dos novos sujeitos de direito no campo da tecnologia assistiva.

Questiona-se, num primeiro momento, a eficácia da emancipação social dos sujeitos com deficiência física ou mobilidade reduzida em face da ineficácia estatal de promover a plena acessibilidade e acesso às tecnologias que permitem a liberdade e fomentam a igualdade de oportunidades.

Notadamente, na pós-modernidade, há um torrente reconhecimento de novos direitos e, consequentemente, carrega em si um certo desencantamento social no que diz respeito à efetividade e à eficácia do conteúdo ético da dignidade humana, especialmente, quando se fala em emancipar um contingente vulnerável como os que necessitam do direito de acesso à cidade e ao contato social permanente na sociedade informacional.

Desta maneira, avulta importante a investigação e o inventário acerca das premissas políticas, culturais, econômicas e sociais que, invariavelmente, orientam as ações e as políticas do Estado, em particular, com as promessas constitucionais decorrentes de novas ideologias que marcam as teorias do Estado, da cidadania e dos direitos humanos (Cf. WOLKMER, 2012; BITTAR, 2009). Que reflexões podem ser aprofundadas na perspectiva do empoderamento dos sujeitos com mobilidade reduzida ou deficiência física quando do fomento estatal às tecnologias assistivas?

Com base na ideia do Estado antropologicamente amigo (STRECK; BOLZAN, 2012), é interessante observar como a política pública favorece a inclusão social, facilitando a universalização dos direitos humanos fundamentais. Consoante os dados do IBGE (Instituto Brasileiro de Geografia e Estatística), o Brasil tem 16,27 milhões de pessoas em extrema pobreza, o que corresponde a $8,5 \%$ da população nacional. Ainda segundo o IBGE, há 12.777.207 pessoas portadoras de deficiência ou mobilidade reduzida em nosso país, representando $6,7 \%$ da população total. Esses dados, se dialogados, levam a uma preocupação 
de cunho acadêmico, haja vista que exigem avaliar e compreender a política que trata das medidas includentes em prol do ser humano.

Ora, são pontuais as discussões em torno dos direitos humanos, enaltecendo, subsequentemente, o debate acerca da efetivação dos direitos fundamentais, para além da retórica e da argumentação sociopolítica, em especial, quando se consideram os projetos políticos tendentes a conter ou a atender as diversas pressões sociais.

Quanto à metodologia utilizada para este trabalho de pesquisa, utilizou-se os estudos de Lakatos et. all. (1992). Com relação ao método de abordagem manejado, foi o hipotéticodedutivo, vez que se inicia pela percepção de uma lacuna nos conhecimentos acerca das hipóteses oferecidas, e pelo processo de inferência dedutiva, testa a predição da ocorrência dos fenômenos nelas abrangidos.

Quanto ao método de procedimento, este estudo fez o uso do método histórico e comparativo, visto que, além da abordagem evolutiva da questão concernente ao Estado constitucional e acerca da proteção internacional dos direitos humanos, buscou-se priorizar uma interpretação sistemática dos direitos e das garantias fundamentais, pautados no arcabouço constitucional que atualmente os representa, e relacionando-os com as experiências vivenciadas no direito internacional dos direitos humanos, bem como sua utilidade na implementação de políticas e ações voltadas à inserção da pessoa vulnerável (pessoas com deficiência física ou mobilidade reduzida).

A técnica de pesquisa a ser seguida foi a documentação indireta, pois está respaldada, em boa parte, na interpretação de textos. Ao longo da exposição textual, serão utilizadas as fontes das mais variadas: livros, artigos e periódicos.

Concernente à análise de dados, utilizou-se a leitura formativa, consubstanciada numa análise interpretativa voltada para formação e condensação de elementos na busca do aprofundamento do nosso objeto de estudo.

\section{CONSIDERAÇÕES SOBRE TEORIA E PRÁtiCA DOS DIREITOS HUMANOS E} A PERSPECTIVA DA EMANCIPAÇÃO SOCIAL

A ideia de proteção dos direitos humanos, na maioria das vezes, revela-se como um discurso vazio e destinado, invariavelmente, às questões globais, sem traduzir um efetivo e eficaz instrumento em prol do bem estar da pessoa humana e da comunidade. Essa mesma 
ideologia abrange o direcionamento do direito internacional dos direitos humanos, visto que se exige dos Estados a observância fiel ao sistema protetivo dos direitos humanos firmados na ordem global.

É certo que o direito internacional dos direitos humanos pauta-se em normas internacionais que consagra direitos essenciais e se beneficia de garantias internacionais, institucionalmente, organizadas; ainda, os beneficiários da tutela global (nacionais ou não) estão sob a jurisdição de determinado Estado, que deve respeito a esses preceitos e valores básicos do ser humano, inclusive, disponibilizando aos indivíduos o acesso às instâncias de supervisão e controle da obrigatoriedade estatal, razão pela qual se identificam processos internacionais de proteção aos direitos humanos (RAMOS, 2013).

Nesse contexto, percebe-se que há estudiosos que realçam os direitos humanos são reivindicações morais da sociedade e nascem quando devem e podem nascer (Cf. PIOVESAN, 2005; BOBBIO, 1992). Assim, com a discussão sobre a concepção de direitos, é importante acrescentar que os direitos humanos, contemporaneamente, segundo a visão de Herrera Flores (2002), integram uma racionalidade de resistência, flexibilizando, pois, os processos relacionados à luta pela dignidade humana, visto que se observa a gramática da inclusão e da emancipação do sujeito.

Nitidamente, dentro do marco teórico crítico marxista, compreende-se os direitos humanos considerando a constituição dos mesmos como fruto de processos históricos, conquistas e lutas por dignidade, bens e direitos.

A vida humana, institucionalizada como atributo do cidadão planetário, tem especial status de dignidade e, consequentemente, exige seu reconhecimento para fazer parte da comunidade humana. Assim, entendida a pessoa humana nessa condição de dignidade, ela se torna o foco central da vida e do poder em sociedade, “[...] independente, livre e senhor de seu destino [...]" (NOGUEIRA, 2012, p. 39). Desta maneira, as tecnologias assistivas podem conduzir, naturalmente, esse processo de dignidade e, particularmente, de emancipação das pessoas com deficiência ou mobilidade reduzida.

$\mathrm{Na}$ visão de Coccurutto, tem-se que, ao se reconhecer e constituir a dignidade humana como preceito fundamental do sistema positivado, “[...] o constituinte impõe a necessidade de que se afaste toda situação que reduza as liberdades fundamentais ou desconsidere a realização plena e igualitária da pessoa no âmbito social” (COCCURUTTO, 2010, p. 45). 
Sem dúvida, a própria ampliação de conceitos que norteiam os paradigmas de universalidade e de indivisibilidade oriundas dos direitos humanos revela, não raro, um desafio de ordem prática para a sociedade, visto que dilemas (sociais, políticos, culturais, econômicos, dentre outros) que enfraquecem o sentido moral acerca da efetividade e da eficácia dos direitos humanos.

Ademais, os grupos vulneráveis aqui enaltecidos demandam políticas estatais no intuito de fortalecer o acesso pleno às tecnologias que dizem respeito à dignidade e à liberdade e são, pois, sujeitos participativos nos processos políticos e econômicos do Estado de direito.

Santos (1989) esclareceu que os direitos humanos, dentro de um viés dogmática e formalista do Estado, é notabilizado em conceitos e normas genéricas, carecendo de real efetivação, em particular nos Estados cuja cultura jurídica privilegia a legalidade em prejuízo das práticas sociais. Em outros termos, é possível explanar que:

[...] começa a predominar um pensamento de emancipação concreta, um pensamento contextual que não recusa o carácter utópico dos direitos humanos mas exige que a sua utopia, por mais radical, se traduza num quotidiano diferente, no mapa de um novo modo de vida mais autêntico. Paralelamente, torna-se cada vez mais evidente que a luta contra a dominação e a exploração só é eficaz enquanto luta contra a alienação (SANTOS, 1989, p. 9).

Ao destacar práticas participativas, sujeitos políticos emergentes e instituição de novos direitos, Wolkmer (2007) apresenta o repensar das formas de legitimidade que consideram, essencialmente, o surgimento de novos sujeitos de direitos, avaliando também as lutas sociais que buscam a satisfação das necessidades humanas. Sendo assim, o autor embasa seus argumentos a partir da problematização dos conceitos de justiça e de novos direitos, dentro dos recortes da resistência, emancipação e vida digna em face do direito contemporâneo.

Considerando os direitos humanos como promessas da modernidade, Santos compartilha a ideia de que as possibilidades de realização são infinitas, de sorte que existem excesso das promessas legais ou o insuficiente respaldo político para o seu exato e integral cumprimento. Para o autor, esses direitos, possivelmente, são promessas amplamente cumpridas e, concomitantemente, revela o agravamento de outras necessidades não atendidas pelo Estado, gerando crise do projeto de modernidade (Cf. SANTOS, 1989). 
Nestas discussões acerca do ideal de emancipação advindo do direito, desconsiderada a neutralidade da ciência, é curial reconhecer que a sociedade e suas práticas estão reconhecidamente conduzidas por um conjunto plural de culturas e práticas. Em outras palavras, “A importância do pluralismo na perspectiva emancipatória revela o espaço de coexistência para uma compreensão crescente de elementos societários criativos, diferenciados e participativos" (WOLKMER, 2007, p. 99).

Evidenciando os novos contornos para direito moderno, a despeito do seu lado plural e emancipador, um marco importante diz respeito ao entendimento acerca daquilo que seja, realmente, necessidade humana e sua justa satisfação desses direitos. "A estrutura das necessidades humanas que permeia a coletividade refere-se tanto a um processo de subjetividade, modos de vida, desejos e valores, quanto à constante ausência ou vazio de algo almejado e nem sempre realizável”. (WOLKMER, 2006, p. 121-122). Daí por que se conclui o seguinte: as necessidades humanas variam de acordo, espácio-temporalmente, com a sociedade e com a cultura (WOLKMER, 2006; 2007).

Por esta mesma razão, os doutrinadores, em geral, sustentam que os direitos humanos constituem-se em verdadeira invenção da modernidade ou uma das grandes promessas da modernidade, conforme Boaventura Santos (1989).

Mais uma vez, Wolkmer (2006), discutindo o pluralismo jurídico em face do surgimento dos novos direitos no contexto da globalização, observa o direito como expressão da resistência e de afirmação dos chamados direitos humanos emergentes.

Trata-se de repensar um projeto social e político contra-hegemônico, capaz de reordenar as relações tradicionais entre Estado e Sociedade, entre o universalismo ético e o relativismo, cultural, entre a razão prática e a filosofia do sujeito, entre o discurso de integração, e de diversidade, entre as formas convencionais de legalidade e as experiências plurais não-formais de jurisdição. (WOLKMER, 2006, p. 113-114).

Apesar dos objetivos (políticos, econômicos, sociais) do Estado e das fundadas razões da expressão do poder do mercado, certamente há de verificar outras notáveis modalidades de experiência comunitária e normatizações das práticas sociojurídicas relacionadas a direitos emergentes. Neste mesmo sentido, Wolkmer compreende a força da sociedade "como novo espaço comunitário de efetivação da pluralidade democrática, comprometida com a alteridade e com a diversidade cultural" (2006, p. 114). 
Eis o motivo por que o pluralismo normativo tem se destacado como um dos fenômenos dentre as formas de controle social, punição e prevenção de conflitos. Certo é que constatação de Wolkmer acena o seguinte:

[...] o pluralismo comprometido com a alteridade e com a diversidade cultural projeta-se como instrumento contra-hegemônico, porquanto mobiliza concretamente a relação mais direta entre novos sujeitos sociais e poder institucional, favorecendo a radicalização de um processo comunitário participativo, definindo mecanismos plurais de exercício democrático e viabilizando cenários de reconhecimento e de afirmação de Direitos Humanos. (WOLKMER, 2006, p. 114).

Justamente, a base paradigmática decorrente do fenômeno do pluralismo normativo, permeado a partir do viés comunitário-participativo, com abertura dialógica entre culturas, possibilita novos debates e concepções em volta dos direitos humanos.

A despeito de constatar a questão positiva do avanço da emancipação em torno dos direitos humanos no cenário pós-guerra, historicamente, compreende-se que a linguagem relativa aos direitos confundiu-se com chavão, sobretudo entendida sua articulação dentro dos parâmetros políticos influenciados pela guerra fria. Além do mais, a mesma retórica de direitos serviu de escudo ou arma para combater os inimigos do sistema vigente.

\footnotetext{
Os piores abusos, omissões e transgressões são de responsabilidade do Estado, tomado aqui como a autoridade governante (polícia, judiciário, legislativo, serviços públicos e política externa) que nasce de alguma forma de pacto social. A presença e o poder da autoridade estatal são tão dominantes em todas as esferas de nossas vidas que os direitos humanos freqüentemente são concebidos como um conjunto de princípios, ou pactos, entre o Estado e os que são governados por ele (VIEIRA; SCOTT DUPREE, 2004, p. 50)
}

Por outro lado, a crise do pensamento monolítico, estatista e centralizador do direito oficial (formal) cede espaço à compreensão de que o respeito e a promoção dos direitos humanos são capazes de incluir novos sujeitos sociais e a luta por eles. Vieira (2004) observa que:

\footnotetext{
A ilusão de que o Estado é a única parte responsável pelos direitos humanos deveria ser desfeita de vez. A autoridade está em qualquer poder que um indivíduo ou um grupo detenha sobre outro, e não unicamente no poder do Estado. Os grupos sociais detêm essa autoridade sobre seus membros. O Estado pode restringir ou desencorajar seus abusos, mas não isentá-los do poder que exercem. Nossa hipótese deve explicar também por que essas forças sociais, que agrupadas formal ou informalmente compõem um nível de "autoridade", não respeitam os direitos humanos. (VIEIRA; SCOTT DUPREE, 2004, p. 50-51)
} 
Vieira e Dupree (2004) destacam a forma de demonização dos direitos dos excluídos, visto que relutam o status quo da classe dominante. Há, assim, um temor da classe privilegiada que identifica a força em potencial e o quantificativo das populações, economicamente, vulneráveis representam um problema a ser combalido pelo direito classista e formalista, inclusive se socorrendo da violência (institucional ou física), com a finalidade de combater os grupos e movimentos sedentos de justiça social. Para a classe dominante e detentora do poder, interessa a invisibilidade social desses sujeitos, que devem apenas respeito às normas e aos padrões impostos pelo Direito.

Exsurge, assim, a necessidade de ampliação de espaços de luta para reivindicação de direitos e garantias, em particular, para os grupos vulneráveis, o que se apresenta dificuldades de concessão de direitos pelo Estado, visto que alega, geralmente, impossibilidade financeira para atender, prontamente, às demandas. No caso do fomento e apoio às tecnologias assistivas, impõe-se, sim, uma análise com mais cautela.

\section{DA CRISE DO APARELHO ESTATAL E OS EFEITOS COLATERAIS PARA OS DIREITOS HUMANOS}

Com base nos estudos de Cassese, a crise do Estado pode ser apontada, desde o início do século XX, por meios de cinco características: a) surgimento de organizações fortes (sindicais e industriais), contestadoras da soberania estatal; b) limitação imposta ao Estado diante do surgimento dos denominados poderes públicos internacionais, a despeito desse poder ser instituído e ratificado pelo próprio Estado; c) crescente inadequação dos serviços estatais no que se relaciona com às expectativas da sociedade; d) polissemia da palavra Estado redundou no desprestígio para o interesse acadêmico em se discutir a crise, visto que a falta de unidade conceitual abarcaria outras figuras, instituições e entidades; e) início da diminuição dos serviços estatais, considerando as privatizações e outras maneiras de concessão de serviços públicos essenciais agora a cargo do setor privado (CASSESE, 2010, p. 14).

Concorda-se com a posição de Cassese (2010), ao observar que a crise do Estado revela a perda da unidade do poder público (em especial, a função executiva) no contexto interno e a perda da soberania em relação ao exterior. Esta crise de controle dos aparelhos públicos, reconhecendo, ainda, o surgimento concomitante de autoridades independentes (principalmente, da arena econômica), demonstra, claramente, os desafios impostos pela nova ordem socioeconômica. 
Sendo assim, a corrupção política, a cultura coronelista, as novas ideologias políticas de direita, a burocratização do aparelho estatal, dentre outros vícios institucionais e sociais, redesenham um novo marco para a construção e acatamento dos direitos humanos, na sua linguagem e na sua gramática. Esse padecimento da sociedade remete à politização destorcida acerca da política democrática e, igualmente, da efetivação de direitos sociais, em particular no que diz respeito à saúde, à educação, à previdência, ao trabalho, ao acesso à cultura e ao lazer etc.

À medida que se destaca a crítica em favor do plural e do emancipatório em torno do direito enquanto instrumento de justiça distributiva, pode-se dialogar com pensamento de Wolkmer (2007), quem considera a existência crise de hegemonias na Modernidade da seguinte forma: i) crise institucional (Estado, Democracia representativa); ii) crise axiológica (fundamentos, princípios, ética); iii) crise de justiça.

A agenda das políticas públicas do Brasil, nas últimas décadas, enaltece, de certo modo, o paternalismo que, possivelmente, pode restaurar a legitimidade da máquina estatal, em face das várias inadequações das ações e programas sociais voltados à inclusão social, além da antipatia social quanto à política fiscal e tributária positivadas e mal discutidas com a própria sociedade.

Mesmo em se discutindo a fragmentação estatal e a questão dos poderes independentes, não se pretende, a todo custo, dogmatizar a questão da soberania no âmbito da mundialização econômica. Entretanto, é necessário pontuar que existe crise e daí decorre consequências de toda ordem de fatores no contexto de um Estado que controla e que protege.

\footnotetext{
Nos últimos 25 anos, foram registradas três modificações importantes nas relações entre Estado e economia. Antes o Estado era soberano no que se referia a economia, agora perdeu essa posição justamente a favor da economia; antes ele era principalmente pedagogo, agora é sobretudo regulador; e o governo que antes era unitário, passou a ser fragmentado (CASSESE, 2010, p. 45).
}

Deste modo, os canais de controle social, institucionalmente, são vistos pela sociedade como formas burocráticas e inacessíveis ao administrado, de forma que as demandas sociais, mais intensivamente a partir de 2010, nascem de protestos sociais (pacíficos ou não), seja nas ruas e, mais popularmente, nas mídias e redes sociais. 
Apesar disso, vale destacar que os direitos humanos têm abertura também no direito subjetivo, já não mais exercível pelo Estado, mas também por intermédio dele ou apesar dele, e, frequentemente, contra o Estado, que é atualmente visto como um dos maiores violadores desses direitos, segundo a observação de Nogueira (2012, p. 9).

De toda maneira, precisa-se de avaliar como essas reivindicações sociais estão adequando a linguagem e o discurso em favor do pensamento ocidental a respeito dos direitos humanos. Indiscutivelmente, não se espera um esvaziamento das conquistas legais em torno dos direitos fundamentais a pretexto da incompetência político-administrativa do Estado, conforme anteriormente foi exposto.

Neste sentido, oportuna é a análise acerca dos processos desenvolvimentistas nos sistemas políticos em vias de desenvolvimento:

[...] em razão da intensidade das expectativas, das pressões sociais e do caráter particular que tem assumido ultimamente, o processo de desenvolvimento, nos sistemas emergentes, transformou-se em importante e imediata meta política, para a qual se orienta, positiva ou negativamente, o processo político das áreas envolvidas. A necessidade do desenvolvimento, bem como a de controlar suas consequiências, contribui decisivamente para determinar as linhas básicas da ação política nessas regiões. Em meio a uma dinâmica social extremamente crítica, com mazelas historicamente crônicas, o desenvolvimento passou a ser visualizado como o principal antídoto contra a insatisfação popular (BELO, 2007, p. 396).

Trata-se, sim, de rediscutir o papel institucional na perspectiva de abrir diálogo com a sociedade, sem perder de vista a importância teórica e prática do discurso global (ocidental) dos direitos humanos recepcionado pelo Estado brasileiro, corroborando a necessidade de ampliar as ideias em volta do aperfeiçoamento das ações e programas sociais, consolidando e efetivando o princípio da publicidade e da transparência na Administração.

Justamente, a adoção do pensamento crítico, consoante a visão de estudiosos, afasta o senso meramente destrutivo da ideia posta ou da pecha de infundada negação. "Um pensamento crítico é sempre criativo e afirmativo. E, ao afirmar e ao criar, distanciamo-nos daquilo que impede a maioria dos seres humanos de exercer suas capacidades genéricas de fazer e apresentar alternativas à ordem existente". (HERRERA FLORES, 2009, p. 66).

Na seguinte definição de Culleton et. al. (2009, p. 13), os direitos humanos são caracterizados como exigências da condição natural do ser humano e “[...] que, por isso, 
exigem seu reconhecimento, seu respeito e ainda a sua tutela e promoção por parte de todos, mais especialmente daqueles que estejam instituídos em autoridade".

Esta racionalidade, pretensamente crítica, da reflexão pode impulsionar a avaliação em torno do sistema jurídico, visto que se revela instrumento despido de neutralidade, conforme já afirmado. Contudo, necessário é considerar o ser humano não apenas como destinatário das normas, mas, invariavelmente, como agente criativo do próprio sistema.

Em outras palavras, ao se tratar de sistema jurídico, naturalmente enquanto mecanismo de controle social, remete ao afastamento da ideia de neutralidade, em particular, quando a sociedade global tenta se firmar nos valores advindos do pensamento pós-positivista, visto que, dentre outros paradigmas fortalecidos nesta ideologia, reconhece a pessoa humana como ente dotado de valor moral, posta no centro do ordenamento sociopolítico.

\section{TECNOLOGIA ASSISTIVA E A EFETIVIDADE DOS DIREITOS HUMANOS NO BRASIL}

A ISO 9.999/2009 define a tecnologia assistiva como "qualquer produto, instrumento, equipamento ou tecnologia adaptado ou especialmente projetado para melhorar a funcionalidade de uma pessoa incapacitada". Por seu turno, há positivação no âmbito internacional na Organização Mundial de Saúde: "qualquer produto, instrumento, equipamento ou sistema técnico utilizado por uma pessoa incapacitada, especialmente produzido ou geralmente disponível, que evite, compense, monitore, alivie ou neutralize a incapacidade” (OMS, 2009).

Com frequência diária, são usadas as expressões tecnologia assistiva, ajudas técnicas e tecnologia de apoio como sinônimas. Ademais, na legislação brasileira utiliza a expressão “ajudas técnicas", a exemplo do Decreto n. 3.298 de 1999 e no Decreto n. 5.296/2004, os quais regulamentam, respectivamente, as Leis n.10.048/2000 e 10.098/2000.

O Decreto n. 3.298/1999, conforme disposto no artigo 19, conceitua ajudas técnicas como: "Os elementos que permitem compensar uma ou mais limitações funcionais motoras, sensoriais ou mentais da pessoa portadora de deficiência, com o objetivo de superar as barreiras de comunicação e da mobilidade e de possibilitar sua plena inclusão social" (CEDIPOD, 2007).

Já o Decreto n. 5296/2004 exprime o conceito seguinte, disposto no artigo 61: “[...] consideram-se ajudas técnicas os produtos, instrumentos, equipamentos ou tecnologia 
adaptados ou especialmente projetados para melhorar a funcionalidade da pessoa portadora de deficiência ou com mobilidade reduzida, favorecendo a autonomia pessoal, total ou assistida" (BRASIL, 2004).

A partir dessas inferências, importa compreender melhor a facilitação do avanço dos estudos em torno da chamada tecnologia assistiva, traduzida como o conjunto de recursos e serviços que contribuem para facilitar ou ampliar as habilidades funcionais de pessoas com deficiência, promovendo a qualidade de vida.

Por essa razão, afirma-se que toda a normatização jurídica acerca da tecnologia assistiva compreende muito além do regramento acerca de equipamentos e serviços favorecedores da locomoção de pessoas com deficiência física. Especificamente, compreende toda salvaguarda jurídica em prol da inclusão social, combatendo-se, veementemente, a discriminação (SALA, 2012).

No plano global, a Convenção Internacional sobre os Direitos das Pessoas com Deficiência das Nações Unidas e seu Protocolo Facultativo, firmados em Nova Iorque, em vigor a partir de maio de 2008, objetivou promover, proteger e assegurar o pleno usufruto e isonômico de todos os direitos e liberdades a qualquer pessoa com deficiência.

A doutrina expõe um conceito compatível com o da legislação, porém considera as ajudas técnicas como um setor da tecnologia orientado à busca de soluções no campo da acessibilidade integral, tendo como usuário um público universal, mas que, especificamente, orienta-se principalmente para as pessoas com deficiência e para os idosos (SALA, 2012, p. 146; 2011, p. 161). Nesta pesquisa, intenta-se o fortalecimento da difusão destas tecnologias como mecanismo de favorecer a cidadania e a emancipação social dos sujeitos.

Reforça-se, então, que os ideais de liberdade, igualdade e fraternidade sejam revisitados no âmbito da efetividade dos direitos humanos, uma vez que se impõe o respeito a esses direitos em face do Estado e da sociedade, integrando o leque dos direitos individuais, determinando-se a observância também de deveres individuais a eles correlatos, dentre eles o "[...] dever de manutenção da própria vida, e o de ajudar a viver quando o outro ainda não tem, ou não mais tem capacidade de fazê-lo autonomamente [...]" (SILVA, 2003, p. 23), bem como a questão do direito de solidariedade (fraternidade) no foco dos direitos transindividuais. 
Em especial, a tônica da promoção da igualdade e o acesso igualitário aos serviços e aos bens da vida estão pautadas, firmemente, nos debates contemporâneos de acesso à justiça, de sorte que o debate em face da necessidade do reconhecimento do outro e da redistribuição por intermédio da justiça distributiva (SANTOS, 2003), invariavelmente, permite o cumprimento da agenda do Estado, a fim de que se possa realizar o princípio da isonomia.

Conforme a definição de tecnologia assistiva abordada anteriormente, a produção oriunda das pesquisas da neurociência enquadra-se, perfeitamente, nesse universo tecnológico, tanto que "[...] os serviços são aqueles prestados profissionalmente à pessoa com deficiência visando selecionar, obter ou usar um instrumento de tecnologia assistiva. Como exemplo [...] experimentação e treinamento de novos equipamentos" (SALA, 2012, p. 147).

Com base no pensamento de Herrera Flores (2009), é possível entender que o direito dos direitos humanos está traduzido enquanto técnica, afora outros mecanismos dispostos aos sujeitos sociais, no momento de se buscar a garantia do êxito relacionados aos reclames sociais. Esse mesmo processo de lutas e reivindicações não se caracteriza, repita-se, como instrumentos neutros, especialmente considerando os detentores do poder.

Ao revés, não se afasta a ideia de que os direitos humanos podem servir como discurso capaz de atender a interesses do poder econômico excludente, entretanto, é plenamente viável refletir, por meio da criticidade, o papel emancipatório que carrega o mesmo discurso, haja vista ser premente se pensar em participação no ambiente da política do Estado. Ora, há reflexões que consideram a dualidade dos direitos humanos como instrumento excludente, assim como o mercado e a tecnologia, mas, não carrega consigo o ideário emancipatório (Cf. HOBSBAWN, 2007).

Nesta mesma base de ideias emancipatórias, expõe Costas Douzinas (2009, p. 19) que: "Os direitos humanos se tornam o princípio de libertação da opressão e da dominação, o grito de guerra dos sem-teto e dos destituídos, o programa político dos revolucionários e dissidentes". Estas mesmas inferências podem ser dialogadas com o pensamento de Wolkmer, para quem:

As novas formas perversas de colonização geradas pela globalização, favorece ações ordenadas e estratégias contra-hegemônicas, incorporadas pela representação configurada nos chamados novos movimentos sociais, fonte que se legítima para engendrar práticas de Justiça descentralizadora e direitos insurgentes, bem como para viabilizar experiências legitimadoras de resistência ao desenfreado processo de desregulamentação e desconstitucionalização da vida (WOLKMER, 2007, p. 102). 
Ao considerar o engajamento do Brasil na sistemática interamericana de direitos humanos, mais precisamente a partir da década de 1990, deparamos com diversos conflitos de violação de direitos são apreciados pelos instrumentos de monitoramento, abrindo o leque de ações paradigmáticas em favor do respeito e da promoção dos direitos fundamentais. Assim, importa, para fins de análise crítica, a visão panorâmica sobre o universo dos direitos humanos (Cf. VIEIRA, 2002), para tomar uma certa conscientização e formular hipóteses para os problemas pelos quais nos desafiam.

Em verdade, o que se difunde é o ideal de superação das desigualdades, a fim de combater privilégios e o poder arbitrário do Estado, formatando uma nova concepção de direito que promova transformação socioeconômica e, em particular, facilite a igualdade e, ao mesmo tempo, respeito as diferenças. Acrescente que, segundo uma perspectiva crítica, o Estado dota de uma função legítima, especialmente no sentido de reconhecer que:

[...] os direitos tendem a estabelecer relações horizontais e de reciprocidade, em contrapartida com as relações verticais e hierarquizadas decorrentes de um universo regulado por privilégios. Evidente que essas características da gramática dos direitos se colocam num plano ideal, e muitas vezes o que chamamos de direitos funcionam na realidade como privilégios. (VIEIRA, 2002, p. 15).

Ainda, é importante salientar a dúvida acerca do acesso às tecnologias constitui, de plano, um direito subjetivo, a despeito de a legislação subordinar o atendimento do referido direito à disponibilidade orçamentária do Poder Público. Em verdade, como se refere a proteção da dignidade humana para os sujeitos com patologia física, é urgente que políticas sejam direcionadas a massificar esse acesso, de forma que a sistemática dos direitos humanos imponha que o Estado dê pronta resposta aos desafios impostos pela realidade apresentada.

A esse respeito, mencione-se que, no Brasil, a partir de 2012, houve investimento no sentido de incentivar os projetos e pesquisas para aperfeiçoar a política de acessibilidade em nome dos direitos humanos. Um exemplo são as ações da Financiadora de Estudos e Projetos - FINEP, empresa pública vinculada ao Ministério da Ciência, Tecnologia e Inovação MCTI, que tem por missão promover o desenvolvimento socioeconômico através do fomento público à Ciência, Tecnologia e Inovação em empresas, universidades, institutos tecnológicos e outras instituições (públicas ou privadas). 
Realmente, observa-se que a bioética pode servir de instrumento que venha facilitar a compreensão dos destinos da vida humana de portadores de patologias que restringem o aparelho locomotor, considerando que os fins das pesquisas não são econômicos e sim científicos, particularmente com a finalidade de promover a felicidade das pessoas em situação vulnerável, tais como as com mobilidade reduzida.

\section{CONSIDERAÇÕES FINAIS}

É pontual, então, questionar como que a sociedade global pode enfrentar as crises pelas quais enfraquecem o discurso dos direitos humanos enquanto instrumento de promoção e provimento da igualdade e, ao mesmo tempo, o respeito às diferenças entre os povos.

Com base nas informações expostas, verifica-se que, na seara da crise estatal brasileira, a carga ideológica dos direitos humanos reorienta as ações políticas, permitindo que haja a abertura de diálogo pelo qual se respeite o interesse público, contendo os protestos e insurgências populares. Geralmente, emerge a crise da legitimidade do Estado é caracterizada pelo despreparo político na condução da coisa pública e a partir da abertura para novos direitos e novos atores sociais que ampliam as demandas perante o Estado.

Propõe-se o reforço e o incentivo permanente pelo Estado à tecnologia assistiva, visto que é uma das formas de salvaguardar, proteger e promover os direitos fundamentais à vida e à liberdade da pessoa com deficiência ou mobilidade reduzida. Nesse norte de ideias, então, não se afastam, invariavelmente, as questões bioéticas, não raras à investigação acerca da efi- cácia e efetividade dos direitos humanos.

Torna-se contraditório que os direitos humanos sejam, sistematicamente, respeitados se não houver um conjunto de condições sociais e políticas em favor de grupos vulneráveis. Desta maneira, para que prevaleça a interpretação e aplicação do direito pro homine, equacionando as demandas sociais e respeitando um padrão mínimo de equilíbrio social.

Embora o Brasil tenha dado alguns passos quanto ao despertar à necessidade de progressos em torno da acessibilidade e da tecnologia assistiva como mecanismos facilitadores da efetividade dos direitos humanos, ainda está muito distante de alcançar o ideal de sociedade igualitária, porquanto os direitos humanos devem ser compreendidos na sua integralidade e isso exige do Estado o investimento contínuo para atender às pesquisas e, consequentemente, às carências dos sujeitos. 
Reconhece-se que, considerando as revoluções tecnocientíficas mais recentes, sem contar com os interesses econômicos e mercadológicos envolvidos, há, concretamente, avanços significativos em prol da qualidade de vida das pessoas com patologias e, particularmente, daquelas com diversidades funcionais. Sem dúvida, o que se espera é a eficácia dos ditames jurídicos, em particular aqueles que tratam do favorecimento dos meios para concretizar o acesso aos processos tecnológicos e, por consequência, fortalecer a emancipação da pessoa humana com patologia.

\section{REFERÊNCIAS}

BELO, Manoel Alexandre C. Sistemas transicionais e estratégias de desenvolvimento. Verba Juris, João Pessoa, a. 6, n. 6, p. 395-412, jan./dez. 2007.

BOBBIO, Norberto. Era dos direitos. Tradução Carlos Nelson Coutinho. Rio de Janeiro: Campus, 1992.

CASSESE, Sabino. A crise do Estado. Tradução Ilse Paschoal Moreira e Fernanda Landucci Ortale. Campinas: Saberes, 2010.

CASTELLS, Manuel. Redes de indignação e esperança: os movimentos sociais na era da internet. Tradução Calors Alberto Medeiros. Rio de Janeiro: Zahar, 2013.

COCURUTTO, Ailton. Os princípios da dignidade da pessoa humana e da inclusão social. São Paulo: Malheiros, 2010.

CULlETON, Alfredo; BRAGATO, Fernanda Frizzo; FAJARDO, Sinara Porto. Curso de direitos humanos. São Leopoldo: Unisinos, 2009.

DOUZINAS, Costas. O fim dos direitos humanos. Tradução Luzia Araújo. São Leopoldo: Unisinos, 2009.

FARIAS, José Fernando de Castro. A origem do direito de solidariedade. Rio de Janeiro: Renovar, 1998.

HERRERA FLORES, Joaquim. A re(invenção) dos direitos humanos. Florianópolis: Fundação Boiteux, 2009.

Direitos humanos, interculturalidade e racionalidade de resistência. Seqüência, Florianópolis, V. 23 n. 44, p. 9-29, 2002.

HOBSBAWN, Eric. Globalização, democracia e terrorismo. São Paulo: companhia das Letras, 2007.

NOGUEIRA, Alberto. Uma teoria dos direitos fundamentais. Rio de Janeiro: Renovar, 2012. 
PIOVESAN, Flávia. Ações afirmativas da perspectiva dos direitos humanos. Cadernos de Pesquisa, São Paulo, v. 35, n. 124, p. 43-55, jan./abr. 2005. Disponível em: <http://www.scielo.br/pdf/cp/v35n124/a0435124.pdf> Acesso em: 21 fev. 2015.

SALA, José Blanes. O acesso à tecnologia assistiva como um direito subjetivo do deficiente no âmbito internacional e no nacional. Cadernos de Direito (UNIMEP), Piracicaba, v. 11, p. 159-173, jul./dez. 2011.

Os direitos do deficiente físico e a tecnologia assistiva na norma nacional e internacional. In: BUCCI, Daniela; SALA, José Blanes; CAMPOS, José Ribeiro de (Org.). Direitos humanos: proteção e promoção. São Paulo: Saraiva, p. 143-161. 2012

SANTOS, Boaventura de Sousa. Reconhecer para libertar: os caminhos do cosmopolitanismo multicultural. Por uma concepção multicultural de direitos humanos. Rio de Janeiro: Civilização Brasileira, 2003, p.429-461.

SANTOS, Boaventura de S. Os direitos humanos na pós-modernidade. Oficina do CES, Coimbra, $\quad$ n. $10,1989.1$ mar. Disponível em: http://www.ces.uc.pt/myces/UserFiles/livros/1097_Oficina\%20do\%20CES_10.pdf Acesso em: 12 fev. 2015.

STRECK, Lênio Luiz; MORAIS, José Luis Bolzan de. Ciência Política e Teoria do Estado. 7. ed. Porto Alegre: Livraria do Advogado, 2012.

RAMOS, André de Carvalho. Processo internacional de direitos humanos. 3. ed. São Paulo: Saraiva, 2013.

VIEIRA, Oscar Vilhena. A gramática dos direitos humanos. Boletim Científico da ESMPU, Brasília, a. I $\quad-\quad \mathrm{n}^{\mathrm{o}}$ 4, p. 13-33 - jul./set. 2002. Disponível em: <file:///C:/Users/Windows/Downloads/BC_04_Art02.pdf> Acesso em: 21 fev. 2015.

VIEIRA, Oscar Vilhena; SCOTT DUPREE, A. Reflexões sobre a sociedade civil e os direitos humanos. Sur - Revista Internacional de Direitos Humanos, São Paulo, v. 1, p. 49-69, 2004. Disponível em: http://www.surjournal.org/conteudos/artigos1/port/artigo_oscar.htm Acesso em: 24 fev. 2014.

VIOLA, Solon Annes; PIRES, Thiago V. O Movimento de Direitos Humanos e a Produção da Democracia. In: Tânia Suely Antonelli Marcelino Brabo; Martha dos Reis (Org.). Educação, direitos humanos e exclusão social. Marília: Cultura Acadêmica, 2012, v. 1, p. 23-36.

Os difíceis ecos dos direitos humanos: participação e cultura entre as gerações. Revista Debates (UFRGS), v. 8, p. 83-102, 2014.

WOLKMER, Antonio Carlos. Pluralismo, justiça e legitimidade dos novos direitos. Seqüência, Florianópolis, n. 54, p. 95-106, jul. 2007.

WOLKMER, Antonio Carlos. Pluralismo jurídico, direitos humanos e interculturalidade. Sequiência, Florianópolis, n. 53, p. 113-128, dez. 2006. Disponível em: 
https://periodicos.ufsc.br/index.php/sequencia/article/view/15095/13750 Acesso: 25 fev. 2015. 